\title{
Hepatobiliary Iminodiacetic Acid Scanning Detects High-Grade Biliary Obstruction Secondary to IgG4-Related Sclerosing Cholangitis
}

\author{
Sayf Al-Katib, Zaid Al-Faham, and Farnoosh Sokhandon \\ Department of Diagnostic Radiology and Molecular Imaging, Oakland University William Beaumont School of Medicine, Beaumont \\ Health System, Royal Oak, Michigan
}

\begin{abstract}
In this report, we present a case of high-grade biliary obstruction discovered on hepatobiliary scintigraphy secondary to IgG4-related sclerosing cholangitis with concomitant autoimmune pancreatitis, a recently described entity that is gaining recognition in the radiology literature. To our knowledge, the scintigraphic findings have yet to be described in the literature. We present the hepatobiliary scintigraphic findings and their correlation to findings on endoscopic retrograde cholangiopancreatography, CT, and MR cholangiopancreatography, with posttreatment follow-up imaging. IgG4-related sclerosing cholangitis is a rare yet important diagnostic consideration when high-grade obstruction is seen on hepatobiliary iminodiacetic acid scanning. We discuss the differential diagnosis of highgrade biliary obstruction seen on hepatobiliary iminodiacetic acid scanning.
\end{abstract}

Key Words: IgG4-related sclerosing cholangitis; autoimmune pancreatitis; HIDA scan; biliary obstruction

J Nucl Med Technol 2015; 43:297-298

DOI: 10.2967/jnmt.115.154708

$\mathbf{I}_{8}$

G4-related sclerosing cholangitis is a form of cholangitis caused by infiltration of IgG4-positive plasma cells, which is commonly associated with autoimmune pancreatitis (1). This condition results in biliary strictures, most commonly affecting the distal common bile duct (2).

\section{CASE REPORT}

A 35-y-old man with no significant past medical history presented to the emergency department with painless jaundice. Physical examination revealed scleral icterus. Laboratory studies were remarkable for an aspartate aminotransferase level of $282 \mathrm{U} / \mathrm{L}$, an alanine aminotransferase level of $696 \mathrm{U} / \mathrm{L}$,

\footnotetext{
Received Feb. 3, 2015; revision accepted Mar. 10, 2015

For correspondence or reprints contact: Sayf Al-katib, Department of Diagnostic Radiology and Molecular Imaging, Oakland University William Beaumont School of Medicine, Beaumont Health System, 3601 W. 13 Mile Rd., Royal Oak, Ml 48073.

E-mail: sayf.al-katib@beaumont.edu.

Published online Apr. 9, 2015.

COPYRIGHT (C 2015 by the Society of Nuclear Medicine and Molecular Imaging, Inc.
}

an alkaline phosphatase level of $249 \mathrm{U} / \mathrm{L}$, and a total bilirubin level of $9.9 \mathrm{mg} / \mathrm{dL}$.

${ }^{99 \mathrm{~m}} \mathrm{Tc}$-disofenin hepatobiliary scanning was initially performed in the emergency department for further evaluation. After intravenous administration of $196.1 \mathrm{MBq}(5.3 \mathrm{mCi})$ of ${ }^{99 \mathrm{~m}} \mathrm{Tc}$-disofenin, anterior and posterior spot views were obtained along with dynamic 30-min images and delayed images at $40 \mathrm{~min}, 60 \mathrm{~min}, 4 \mathrm{~h}$, and $24 \mathrm{~h}$.

\section{DISCUSSION}

The dynamic images obtained after injection of ${ }^{99 m} \mathrm{Tc}-$ disofenin showed rapid hepatic uptake of radiotracer. The additional spot images obtained at 40, 60, and $240 \mathrm{~min}$ showed lack of radiotracer accumulation in the gallbladder and small bowel (Figs. 1A-1C). Only on the delayed 24-h image was radiotracer activity present in the gallbladder; however, none was present in the small bowel, consistent with high-grade biliary obstruction (arrow in Fig. 1).

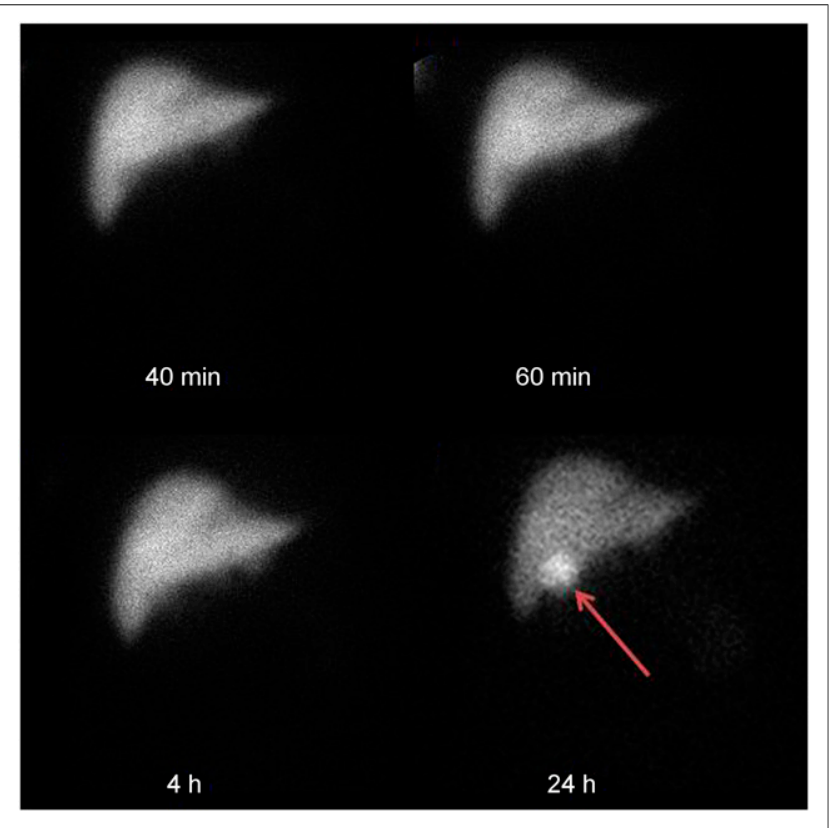

FIGURE 1. Spot images obtained during 99mTc-disofenin scanning show lack of radiotracer activity in small bowel. Activity in gallbladder (arrow) is first seen on delayed 24-h image. 


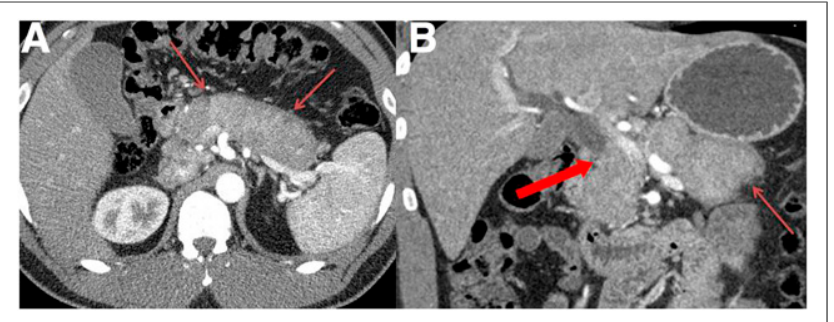

FIGURE 2. Axial (A) and coronal (B) contrast-enhanced CT images of abdomen show diffusely enlarged, sausage-shaped pancreas with loss of lobulation and presence of lowattenuation peripancreatic halo (thin arrows). Common bile duct is dilated, with abrupt change in caliber (thick arrow).

The patient subsequently underwent a contrast-enhanced CT study of the abdomen (Fig. 2). The images revealed a diffusely enlarged, sausage-shaped pancreas with loss of normal lobulation and the presence of a peripancreatic lowattenuation halo compatible with autoimmune pancreatitis. In addition, the common bile duct was dilated, measuring $14 \mathrm{~mm}$, with an abrupt change in caliber distally. Endoscopic retrograde cholangiopancreatography and MR cholangiopancreatography were also performed and confirmed the focal stricture in the distal common bile duct (Fig. 3).

Given the concern about malignancy, the patient underwent percutaneous core biopsy of the pancreatic head. The finding-periductal and acinar lymphoplasmacytic infiltration with IgG4-positive cells-confirmed the diagnosis of IgG4-related sclerosing cholangitis with concomitant autoimmune pancreatitis.

The patient subsequently underwent treatment with systemic steroids, which resolved the symptoms and normalized the laboratory levels. Follow-up MR cholangiopancreatography was performed 10 mo after initiation of treatment and showed complete resolution of the focal

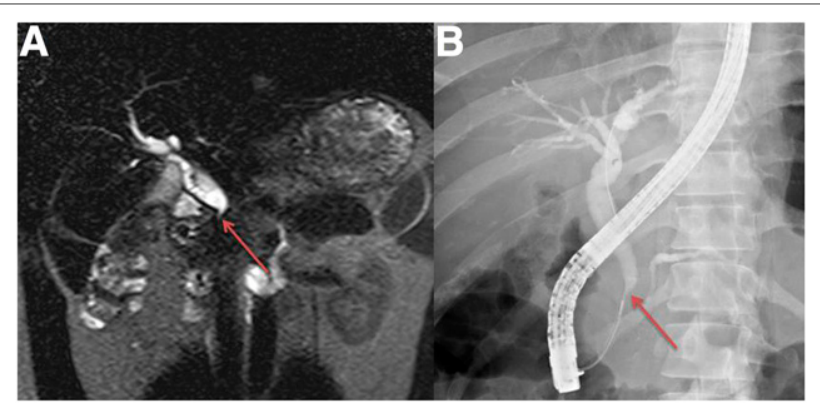

FIGURE 3. Coronal thin-slab MR cholangiopancreatography image (A) and spot image from endoscopic retrograde cholangiopancreatography (B) confirm focal stricture of distal common bile duct (arrows).

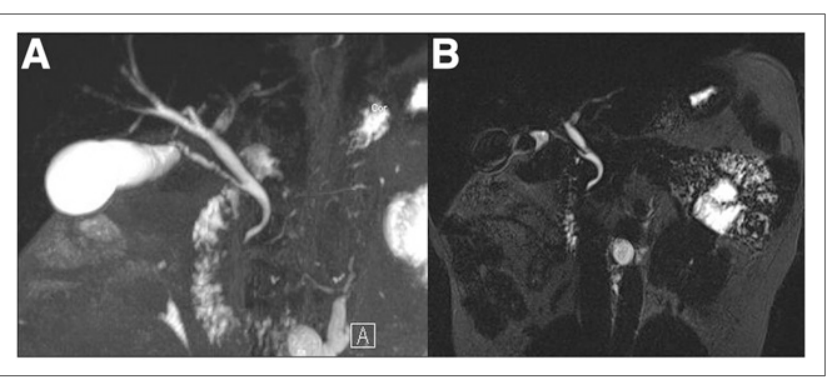

FIGURE 4. Maximum-intensity-projection image (A) and coronal thin-slab MR cholangiopancreatography image (B) obtained 10 mo after initiation of treatment with systemic steroids show resolution of biliary stricture.

stricture in the common bile duct and normalization of the pancreas morphology (Fig. 4).

The utility of scintigraphy in cases of jaundice lies in its ability to distinguish among completely obstructive, partially obstructive, and nonobstructive causes (3). Many causes of high-grade biliary obstruction can be detected on hepatobiliary iminodiacetic acid scanning, one of which is IgG4-related sclerosing cholangitis. These causes can be intrahepatic, such as hepatitis or cirrhosis, or extrahepatic, such as biliary strictures, choledocholithiasis, and obstructing masses (4).

\section{CONCLUSION}

High-grade biliary obstruction has multiple etiologies including neoplastic and inflammatory conditions. One should consider IgG4-related sclerosing cholangitis in the differential diagnosis of high-grade and partial biliary obstruction on hepatobiliary iminodiacetic acid scanning and use additional imaging modalities to obtain an accurate diagnosis.

\section{DISCLOSURE}

No potential conflict of interest relevant to this article was reported.

\section{REFERENCES}

1. Okazaki K, Uchida K, Koyabu M, Miyoshi H, Ikeura T, Takaoka M. IgG4 cholangiopathy: current concept, diagnosis, and pathogenesis. J Hepatol. 2014;61: 690-695.

2. Katabathina VS, Dasyam AK, Dasyam N, Hosseinzadeh K. Adult bile duct strictures: role of MR imaging and MR cholangiopancreatography in characterization. Radiographics. 2014;34:565-586.

3. Lee AW, Ram MD, Shih WJ, Murphy K. Technetium-99m BIDA biliary scintigraphy in the evaluation of the jaundiced patient. J Nucl Med. 1986;27: 1407-1412.

4. Matthews R, Goodman M, Relan P, et al. Tc-99m mebrofenin hepatobiliary scan in obstructive hepatobiliary disease: determining causes with early and late delayed imaging. World J Nucl Med. 2013;12:54-56. 